\title{
PRUEBA DE CONCEPTO DE UNA PCR MULTIPLEX DE PRIMERA GENERACIÓN (CUALITATIVA) PARA DETECCIÓN DEL ONCOGÉN E7 DE VPHS DE ALTO RIESGO
}

Recibido: noviembre del 2018

Aceptado: abril del 2019

Brigitte Ofelia Peña López ${ }^{1}$, Laura Melissa Torrado García², Ruth Aralí Martínez Vega ${ }^{3}$, Bladimiro Rincón Orozco ${ }^{4}$

\section{Resumen}

Introducción: Infección persistente con el virus de papiloma humano de alto riesgo (VPH-AR) causa cáncer de cuello uterino (CCU). Existen ensayos moleculares para la detección y la genotipificación del gen L1 de VPH, sin embargo, L1 puede perderse durante la integración viral. La expresión e integración del oncogén E7 es fundamental para el desarrollo de CCU. Objetivo: Estandarizar una PCR multiplex (mPCR) del oncogén E7 (E7-mPCR) para genotipificación de los VPH-AR de mayor frecuencia en CCU (VPH-16, -18, -31, -33, -45 y -52). Métodos: Se obtuvieron cepillados cervicales de voluntarias y se analizaron amplificando por PCR el gen L1 con subsecuente hibridación reversa. Posteriormente, se escogieron 59 muestras positivas para VPH-AR y se analizaron por E7-mPCR. Resultados: Se evidenció una elevada concordancia entre los resultados del ensayo E7mPCR y los de la PCR de L1 (concordancia observada de 95,1\%, Kappa de Cohen $=0,88$ ), encontrándose mayor número de infecciones por VPHAR en el 15,8\% con E7-mPCR. Conclusión: E7-mPCR es una herramienta diagnóstica con alta concordancia y económica que puede adaptarse a una plataforma de mayor complejidad para procesar y detectar mayor cantidad de muestras y genotipos de VPH-AR.

Palabras clave: VPH, Genotipificación, Neoplasias del Cuello Uterino, Reacción en Cadena de la Polimerasa Multiplex, gen L1, gen E7.

${ }^{1}$ Microbióloga y bioanalista.

${ }^{2}$ Microbióloga y bioanalista. Magíster en Enfermedades Infecciosas.

${ }^{3}$ Médica, magíster en Epidemiología, doctora en Ciencias de la Salud Pública con área de concentración en Enfermedades Infecciosas. Profesora asistente de la Universidad Industrial de Santander.

4 Bacteriólogo y laboratorista clínico. Magíster en Ciencias Biomédicas, doctor en Inmunología. Profesor titular de la Universidad Industrial de Santander. Correo electrónico: blrincon@uis.edu.co 


\section{CONCEPT TESTING OF A MULTIPLE PCR OF FIRST GENERATION (QUALITATIVE) FOR DETECTING E7 ONCOGENE OF HIGH-RISK HPV}

Brigitte Ofelia Peña López ${ }^{1}$, Laura Melissa Torrado García², Ruth Aralí Martínez Vega ${ }^{3}$, Bladimiro Rincón Orozco ${ }^{4}$

\section{Abstract}

Introduction: The persistent infection of the high-risk Human Papiloma Virus (VPH-AR in Spanish) causes uterine cervix cancer (CCU in Spanish). There are molecular essays for detection and genotyping of gen L1 of VPH. However, L1 may get lost during the viral integration. The expression and integration of oncogene E7 is fundamental for the development of CCU. Objective: To standardize a multiplex PCR (mPCR) of oncogene E7 (E7-mPCR) for genotyping the VPHAR of highest frequency in CCU (VPH-16, -18, -31, -33, -45 y -52). Method: We obtained cervix brushing simples from volunteers and we analyzed them by amplifying the L1 gene through PCR with a subsequent reverse hybridization. After that, we chose 59 positive $\mathrm{VPH}-$ AR samples and we analyzed them for E7-mPCR. Results: We found out a high concordance between the results of the essay E7-mPCR and those of L1 PC (Observed concordance was of 95.1\%, Cohen's Kappa $=0.88$ ), and we revealed a higher number of infections for VPH-AR in a $15.8 \%$ with E7-mPCR. Conclusion: E7-mPCR is an economic diagnostic tool with high concordance which can be adapted to a platform with more complexity to process and detect a higher number of samples and VPH-AR genotypes. 


\section{TESTE DE CONCEITO DE UMA PCR MULTIPLEX DE PRIMEIRA GERAÇÃO (QUALITATIVA) PARA DETECTAR ONCOGÊNESE E7 DE HVP DE ALTO RISCO}

Brigitte Ofelia Peña López ${ }^{1}$, Laura Melissa Torrado García², Ruth Aralí Martínez Vega ${ }^{3}$, Bladimiro Rincón Orozco ${ }^{4}$

\section{Resumo}

Introdução: a infecção persistente com o vírus de papiloma humano de alto risco (HPV-AR) causa câncer de colo do útero (CCU). Existem ensaios moleculares para detecção e para a genotipificação do gene L1 de HPV; contudo, L1 pode ser perdido durante a integração viral. A expressão e integração do oncogênese E7 é fundamental para o desenvolvimento do CCU. Objetivo: padronizar uma PCR multiplex (mPCR) do oncogênese E7 (E7-mPCR) para genotipificação dos HPV-AR de maior frequência no CCU (HPV-16, -18, -31, -33, -45 e -52). Métodos: foram realizadas raspagens com escova cervical rodada em voluntárias e foram analisadas a partir da amplificação do gene L1 por PCR com subsequente hibridação inversa. Em seguida, foram escolhidas 59 amostras positivas para HPV-AR, as quais foram analisadas por E7-mPCR. Resultados: foi evidenciada elevada concordância entre os resultados do ensaio E7-mPCR e os da PCR de L1 (concordância observada de 95,1\%, Kappa de Cohen =0,88), encontrando-se maior número de infecções por HPV-AR em 15,8\% com E7-mPCR. Conclusão: E7-mPCR é uma ferramenta diagnóstica com alta concordância e econômica que pode ser adaptada a uma plataforma de maior complexidade para processar e detectar maior quantidade de amostras e genótipos de HPV-AR. 


\section{Introducción}

La infección persistente con virus de papiloma humano de alto riesgo (VPHAR) causa cáncer de cuello uterino (CCU) $(1,2)$ y este es el segundo cáncer más frecuente en mujeres a nivel mundial (3). Actualmente se realiza tamización para detectar lesiones precancerosas por medio de la citología, método realizado habitualmente debido a su alta especificidad $(90 \%)(4,5)$. No obstante, al momento de diagnosticar lesiones escamosas intraepiteliales de grado alto (HSIL) este método alcanza sensibilidad solamente del $50 \%$, principalmente debido a la calidad de la muestra, la pericia del profesional para identificar alteraciones morfológicas y la subjetividad en la interpretación $(5,6)$. Por esta razón se han desarrollado técnicas moleculares con mayor sensibilidad en la detección de tipos específicos de alto riesgo del VPH.

Muchos protocolos de detección se basan en la amplificación del gen L1, debido a que es altamente conservado, sin embargo, el marco de lectura abierto (ORF, open reading frame) de este gen puede perderse en el momento en que el virus se integra en el genoma de la célula hospedadora, fenómeno observado aproximadamente en el $11 \%$ de las infecciones por genotipos de VPH-AR (7-11). Una mPCR del gen E7 de VPH$A R$ podría ofrecer un mejor rendimiento, pues E7 prevalece integrado en todas las células cancerosas, ya que se necesita de la expresión continua de los oncogenes E6 y E7 para que las infecciones sean persistentes y se promueva un fenotipo maligno de las células $(12,13)$.
A continuación se describe un método sencillo, rápido y económico, potencialmente muy sensible y específico para la detección y tipificación de los seis genotipos de VPH-AR de mayor frecuencia en CCU a nivel mundial (VPH -16, -18, -31, -33, -45 y -52), combinando $\mathrm{MPCR}$ de primera generación con oligonucleótidos dirigidos al gen E7, específicos para cada genotipo de VPH y detectados por electroforesis en gel de agarosa.

\section{Materiales y métodos}

\section{Población de estudio y selección de muestras cervicales}

Se obtuvieron muestras de cepillado cervical de mujeres residentes de la zona norte de Bucaramanga, por medio de un dispositivo para auto-toma según el procedimiento y los criterios de inclusión y exclusión descritos previamente (14). Se seleccionaron todas las muestras positivas para VPH $(\mathrm{n}=59)$ que fueron analizadas previamente por amplificación multiplex del gen L1 por PCR, con subsecuente hibridación reversa con la técnica HPV Direct Flow CHIP, hasta el momento de la ejecución del presente estudio.

Se seleccionó una muestra positiva para cada uno de los seis genotipos a detectar y además una muestra negativa para VPH por HPV Direct Flow CHIP para la estandarización de la E7-mPCR. Una vez se estandarizó la técnica, se valoró su desempeño procesando las muestras restantes, de las cuales el $83 \%$ se evaluó por duplicado. 
Detección de VPH y genotipado por HPV Direct Flow CHIP

Las muestras se conservaron en un líquido de preservación celular (ThinPrep), se centrifugaron $500 \mu \mathrm{l}$ de muestra a $3.500 \mathrm{rpm}$ por cinco minutos, se lavaron dos veces en $400 \mu \mathrm{l}$ de solución salina tamponada con fosfato estéril (PBS) y se resuspendieron en $50 \mu \mathrm{L}$ de $\mathrm{PBS}$, según lo indicado por el fabricante (Master diagnóstica, España).

Por medio de una PCR múltiple del segmento de L1 utilizando los cebadores GP5+/GP6+, se amplificaron los genotipos VPH-BR-6, -11, -40, -42, -43, -44, $-54,-55,-61,-62,-67,-69,-70,-71,-72$, $-81,-84$ y -89 y VPH-AR $-16,-18,-26$, $-31,-33,-35,-39,-45,-51,-52,-53,-56$, $-58,-59,-66,-68,-73$ y -82 . La PCR se realizó con $4 \mu \mathrm{L}$ de $\mathrm{ADN}$ extraído con los siguientes ciclos de amplificación:

- 1 ciclo de 10 minutos a $25^{\circ} \mathrm{C}$

- $\quad 1$ ciclo a $94^{\circ} \mathrm{C}$ por 3 minutos

- 15 ciclos de desnaturalización a $94^{\circ} \mathrm{C}$ por 30 segundos, anillamiento a $42^{\circ} \mathrm{C}$ por 30 segundos y elongación a $72^{\circ} \mathrm{C}$ por 30 segundos

- 35 ciclos de desnaturalización a $94^{\circ} \mathrm{C}$ por 30 segundos, anillamiento a $60^{\circ} \mathrm{C}$ por 30 segundos y elongación a $72^{\circ} \mathrm{C}$ por 30 segundos

- $\quad 1$ ciclo a $72^{\circ} \mathrm{C}$ por 5 min y finalmente por $5 \mathrm{~min}$ a $8^{\circ} \mathrm{C}$

Posteriormente, se desnaturalizaron los amplicones biotinilados durante cinco minutos a $95^{\circ} \mathrm{C}$, se enfriaron en hielo durante dos minutos y se hibridaron por transferencia de puntos y detección colorimétrica en membranas CHIP de VPH que contenían cuatro tipos de sondas tridimensionales: para control de hibridación, para el gen de beta-globina, para la secuencia conservada de L1 y las sondas para la detección de VPH específica de genotipo.

La hibridación se realizó usando el equipo semiautomático HybriSpot 12TM (HS12) que une el amplicón biotinilado con las sondas complementarias. La detección colorimétrica se llevó a cabo mediante la adición de sustratos de NBT-BCIP que detectan actividad de fosfatasa alcalina, creando precipitados puros insolubles $(15,16)$.

\section{Extracción de ADN}

Se optimizó un protocolo de extracción de ADN por salting out (17), por el cual se obtuvieron concentraciones de ADN superiores a $50 \mathrm{ng} / \mathrm{uL}$ y un radio de absorbancia a $260 / 280$ por encima de 1,5 , las cuales fueron determinadas en el espectrofotómetro NanoDrop 2000 (Thermo Scientific, USA).

\section{Control de extracción de ADN}

Se confirmó una correcta extracción de ADN y la ausencia de inhibidores de la PCR en las muestras, al amplificar un fragmento de $250 \mathrm{pb}$ del gen de $\beta$-actina humana (tabla 1). Seguidamente se corrió una electroforesis en gel de agarosa, donde todas las muestras fueron positivas para este gen. 
Diseño de oligonucleótidos específicos para E7

Se utilizaron oligonucleótidos para los tipos de VPH 18, -31, -45 y -52 según Paes, et al. (11), por otro lado, para VPH 16 y -33 se diseñaron nuevos oligonucleótidos utilizando la herramienta Primer-blast (tabla 1). Por medio del programa AutoDimer se verificó que no se formaran estructuras secundarias de cebadores.

\section{Amplificación por E7-mPCR}

Se utilizó una PCR Master Mix (Thermo Scientific, DreamTaq Green, 2X) para realizar 20 amplificaciones en las que se modificaron las concentraciones de $\mathrm{MgCl}_{2}(1,5 \mathrm{a} 4 \mathrm{mM})$, cebadores $(0,033 \mathrm{a}$ $1,00 \mu \mathrm{M})$ y $\mathrm{ADN}$ (50 a $250 \mathrm{ng}$ ). Se crearon diferentes programas de PCR en el termociclador multigene gradient (Labnet, NJ, USA), con variación de la temperatura de anillamiento de 58 a $64^{\circ} \mathrm{C}$ y el número de ciclos de 35 a 38 .

\section{Electroforesis en gel de agarosa}

Se utilizó un sistema de electroforesis horizontal Mini-Sub ${ }^{\circledast}$ Cell GT y la fuente de alimentación básica PowerPac (BioRad, Hercules, USA). Se probaron geles con concentraciones de agarosa que variaron de $2,0 \%$ a 3,0\%. Se añadieron a cada uno de los pozos del gel $15 \mathrm{uL}$ de los productos de la PCR y se sirvió un patrón de peso molecular de 100 a 2.000 pb (Promega, Madison, WI USA). Se realizaron 20 electroforesis variando la potencia de 60 a 100 voltios y el tiempo

272 de 40 a 80 minutos. Tras la electroforesis se sumergió el gel de agarosa en una so- lución de bromuro de etidio $(0,4 \mathrm{ug} / \mathrm{mL})$ durante 15 minutos. Posteriormente, se observó la separación de los fragmentos de ADN bajo transiluminador con luz ultravioleta a $260 \mathrm{~nm}$, tomándose evidencia fotográfica.

\section{Método estadístico}

Se calculó la frecuencia de concordancia observada y el coeficiente Kappa de Cohen para evaluar la concordancia entre la prueba VPH direct flow Chip kit y la PCR Multiplex de E7. Se espera un valor de $\mathrm{K}=0$ cuando la concordancia se dé por azar y un valor de $\mathrm{K}=1$ cuando la concordancia sea del $100 \%$. Los valores de $\mathrm{K}>0,80$ representan un acuerdo casi perfecto.

\section{Resultados}

\section{Diseño de oligonucleótidos específicos para E7}

El diseño de los cebadores para VPH 16 y -33 se fundamentó en la alineación de secuencias en la región del gen E7 de cada uno de los genotipos de VPH$A R$, secuencias que fueron obtenidas del GenBank (NCBI, NIH, USA). Los oligonucleótidos tuvieron una longitud que osciló entre 18 y 26 nucleótidos, la temperatura de fusión estuvo entre $58^{\circ} \mathrm{C}$ y $63^{\circ} \mathrm{C}$ y los tamaños de los productos amplificados variaron entre 148 y 400 pb. De igual modo, se escogieron estas secuencias sentido y antisentido, de tal manera que no se dieran inespecificidades, reacciones cruzadas $\mathrm{ni}$ formación de dímeros o bucles entre sí (tabla 1). 
Tabla 1. Secuencias de los cebadores dirigidos a la región E7 de VPH y al gen de $\beta$-actina, temperaturas de fusión, números de acceso y longitudes de los amplicones

\begin{tabular}{|c|c|c|c|c|}
\hline Nombre & $\begin{array}{l}\text { Número de } \\
\text { acceso en } \\
\text { GenBank }^{\mathrm{a}}\end{array}$ & Cebadores & $\operatorname{Tm}(C)$ & $\begin{array}{c}\text { Pares } \\
\text { de } \\
\text { bases }\end{array}$ \\
\hline \multirow[t]{2}{*}{$\beta$-actina } & NM_001101.4 & F: 5' CATGTACGTTGCTATCCAGGC 3' & 59 & 250 \\
\hline & & R: 5' CTCCTTAATGTCACGCACGAT 3' & 58 & \\
\hline \multirow[t]{2}{*}{ VPH-16 } & NC_001526.4 & F: 5' GCAACCAGAGACAACTGATCTCTAC 3' & 60 & 201 \\
\hline & & R: 5' GGTCTTCCAAAGTACGAATGTCTACG 3' & 60 & \\
\hline \multirow[t]{2}{*}{ VPH-18 } & GQ180792.1 & F: 5' CGACGCAGAGAAACACAAGTAT 3' & 60 & 357 \\
\hline & & R: 5' ATTGTTGCTTACTGCTGGGAT 3' & 59 & \\
\hline \multirow[t]{2}{*}{ VPH-31 } & KX638481.1 & F: 5’ GGCAACTGACCTCCACTG 3' & 62 & 228 \\
\hline & & R: 5' ACAGTTGGGGCACACGATT 3' & 63 & \\
\hline \multirow[t]{2}{*}{ VPH-33 } & M12732.1 & F: 5' GGACACAAGCCAACGTTAAAGG 3' & 59 & 148 \\
\hline & & R: 5' AATCAGCTGT GGCTGGTTGT 3' & 60 & \\
\hline \multirow[t]{2}{*}{ VPH-45 } & KC470260.1 & F: 5' AGGCACGGCAAGAAAGACT 3' & 62 & 309 \\
\hline & & R: 5’TCTAAGGTCATCTGCCGAGC 3' & 62 & \\
\hline \multirow[t]{2}{*}{ VPH-52 } & LC373207.1 & F: 5' GACCTGTGACCCAAGTGTAAC 3' & 58 & 400 \\
\hline & & R: 5' GCCTCTACTTCAAACCAGCC 3' & 59 & \\
\hline
\end{tabular}

a GenBank (https://www.ncbi.nim.nih.gov/genbank

Fuente: elaboración propia, utilizando el software Primer-blast del Centro Nacional para la Información Biotecnológica (NCBI, por sus siglas en inglés).

\section{Amplificación por E7-mPCR}

Se estableció, debido a la existencia de bandas específicas en la electroforesis, que la mezcla más apropiada para la E7-mPCR fue aquella que contuviera cinco unidades de Taq ADN polimerasa, $0,2 \mathrm{mM}$ de desoxirribonucleótidos trifosfatados (dNTP), $4 \mathrm{mM}$ de $\mathrm{MgCl}_{2}$, $0,08 \mu \mathrm{M}$ de cada cebador y $150 \mathrm{ng}$ de ADN (tabla 2). 
INVESTIGACIONES ANDINA No. 39, Vol. 21

Tabla 2. Componentes de la reacción de amplificación

\begin{tabular}{|c|c|c|c|}
\hline \multicolumn{2}{|c|}{ Componente PCR } & Concentración & Volumen \\
\hline $\begin{array}{l}\text { DreamTaq Green PCR } \\
\text { Master Mix (2X) }\end{array}$ & $\begin{array}{c}\text { dNTPs } \\
\text { Taq } \\
\text { polimerasa } \\
\mathrm{MgCl}_{2}\end{array}$ & $\begin{array}{c}0,2 \mathrm{mM} \\
5 \mathrm{u} \\
1,5 \mathrm{mM}\end{array}$ & $7,5 \mu \mathrm{L}$ \\
\hline $\mathrm{MgCl}_{\text {2adicional }}$ & & $2,5 \mathrm{mM}$ & $1,5 \mu \mathrm{L}$ \\
\hline Cebadores & & $0,08 \mu \mathrm{M}$ & $1,25 \mu \mathrm{L}$ \\
\hline Agua & & - & $1,75 \mu \mathrm{L}$ \\
\hline ADN & & 150 ng & $3 \mu \mathrm{L}$ \\
\hline Volumen Final & & - & $15 \mu \mathrm{L}$ \\
\hline
\end{tabular}

Fuente: elaboración propia.

El programa de amplificación con resultados más sensibles y específicos se logró llevando a cabo una fase de desnaturalización inicial a $95^{\circ} \mathrm{C}$ durante dos minutos, seguida de 35 ciclos de amplificación (tabla 3), manteniendo la tempe- ratura de extensión a $72{ }^{\circ} \mathrm{C}$ durante siete minutos para permitir la polimerización de fragmentos incompletos y finalmente conservar los productos de la PCR a $4{ }^{\circ} \mathrm{C}$ hasta el momento de realizar la electroforesis.

Tabla 3. Programa de amplificación E7-mPCR

\begin{tabular}{lllc}
\hline \multicolumn{3}{c}{ Programa E7-mPCR } \\
\hline $\mathbf{1}$ ciclo & Desnaturalización inicial & $95^{\circ} \mathrm{C}$ & 2 minutos \\
& Desnaturalización & $95^{\circ} \mathrm{C}$ & 15 segundos \\
35 ciclos & Alineamiento & $62^{\circ} \mathrm{C}$ & 20 segundos \\
& Extensión & $72^{\circ} \mathrm{C}$ & 1 minuto \\
\multirow{1}{*}{$\mathbf{1}$ ciclo } & Extensión final & $72^{\circ} \mathrm{C}$ & 7 minutos \\
& Conservación & $4^{\circ} \mathrm{C}$ & $\infty$ \\
\hline
\end{tabular}




\section{Electroforesis en gel de agarosa}

Se determinó que una concentración del gel de agarosa al 2,5\% con una potencia de 80 voltios y durante 60 minutos, permite una mejor resolución y discriminación de los fragmentos amplificados (figura 1).

(A)

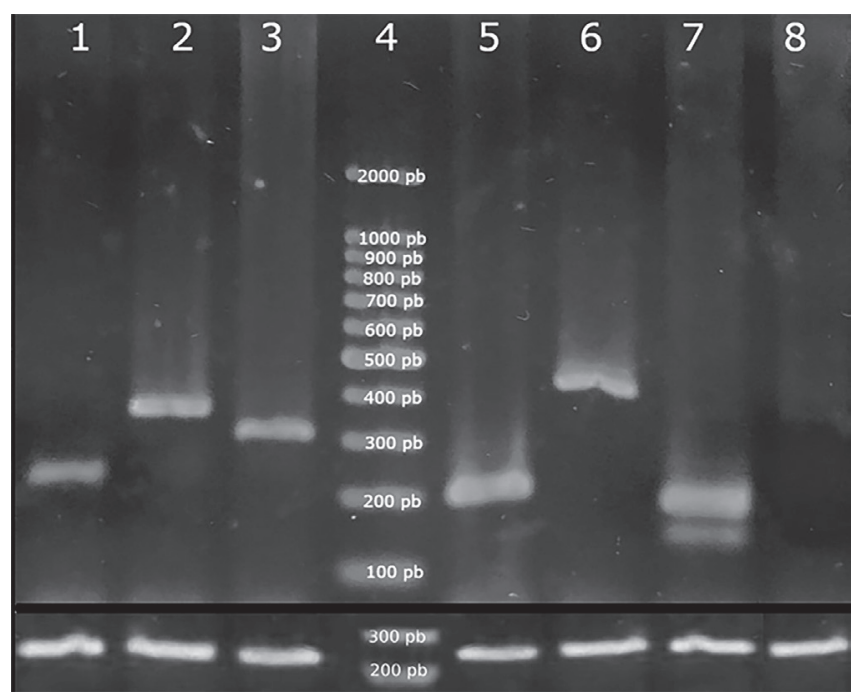

A. Carriles 1, 2 y 3: se observan las bandas correspondientes a los genotipos VPH-31 (228 pb), VPH-18 (357 pb) y VPH-45 (309 pb); Carril 4: marcador de peso molecular; Carriles 5 y 6: Bandas correspondientes a los genotipos VPH-16 (201pb) y VPH-52 (400pb); Carril 7: coinfección VPH-33 (148pb) y VPH-16 (201 pb); Carril 8: control negativo.

B. Bandas correspondientes al fragmento de $250 \mathrm{pb}$ del gen de $\beta$-actina humana.

Figura 1. Genotipificación de 6 VPH-AR mediante E7-mPCR

Fuente: elaboración propia, a partir de análisis experimentales por PCR de primera generación utilizando electroforesis en gel de agarosa.

\section{Selección de las muestras de estudio}

De las 59 muestras seleccionadas de pacientes VPH positivas por amplificación del gen L1 del virus, 11 fueron de genotipo indeterminado, 15 de genotipos correspondientes a los VPH-AR más frecuentes y 33 positivas para otros genotipos (tabla 4).

\section{Evaluación de la E7-mPCR con mues- tras de pacientes}

Del total de las muestras analizadas, el $25,4 \%$ fueron positivas para uno o dos de los seis genotipos de VPH-AR según la PCR del gen L1, en comparación con el $28,8 \%$ por E7-mPCR. Las muestras positivas por PCR de L1 para genotipos diferentes a VPH -16, -18, -31, -33, -45 y -52 (sin incluir los genotipos indeterminados) fueron negativas por E7-mPCR en el 93,9\% de los casos. Así mismo, el $100 \%$ de las muestras de genotipo indeterminado por PCR de L1 fueron negativas por E7-mPCR y no se pudieron clasificar por este método.

Por medio de la E7-mPCR fue posible detectar el ADN viral de tres genotipos 
de VPH-AR (VPH -31, -33 y -52) que no se detectaron mediante amplificación por PCR del gen L1, esto corresponde a un $15,8 \%$ de potenciales falsos negativos para la prueba del gen L1. Además, dos de estas muestras fueron positivas por PCR contra L1 para otros genotipos, ya sea de alto o de bajo riesgo (VPH -59 y -72 , respectivamente) que no están incluidos en la E7-mPCR. La muestra restante fue positiva por PCR de L1 para VPH-31, sin embargo, por E7-mPCR se detectó adicionalmente una coinfección con VPH-52 (tabla 4).

Tabla 1. Selección de las muestras de estudio y resultados por E7-mPCR

\begin{tabular}{|c|c|c|}
\hline Identificación & $\begin{array}{c}\text { Resultado VPH PCR de L1 + } \\
\text { Hibridación reversa }\end{array}$ & $\begin{array}{c}\text { Resultado VPH mPCR de E7 + } \\
\text { Electroforesis }\end{array}$ \\
\hline 1 & AR-16 & AR-16 \\
\hline 2 & AR-16 & AR-16 \\
\hline 3 & AR-16 & AR-16 \\
\hline 4 & AR-16 & AR-16 \\
\hline 5 & AR-16; BR-54 & AR-16 \\
\hline 6 & AR-16; AR-33; BR-44/55 & AR-16; AR-33 \\
\hline 7 & AR-18 & AR-18 \\
\hline 8 & AR-18 & AR-18 \\
\hline 9 & AR-31 & AR-31 \\
\hline 10 & AR-45 & AR-45 \\
\hline 11 & AR-45 & AR-45 \\
\hline 12 & AR-52 & AR-52 \\
\hline 13 & AR-52 & AR-52 \\
\hline 14 & AR-52 & AR-52 \\
\hline 15 & AR-59 & AR-33 \\
\hline 16 & AR-31 & AR-31; AR-52 \\
\hline 17 & BR-72 & AR-31 \\
\hline $18-48$ & $\begin{array}{c}\text { Otros genotipos de VPH-AR o } \\
\text { VPH-BR }\end{array}$ & Negativas para los $6 \mathrm{VPH}-\mathrm{AR}$ \\
\hline $49-59$ & Genotipo indeterminado & Negativas para los $6 \mathrm{VPH}-\mathrm{AR}$ \\
\hline
\end{tabular}

a VPH-AR-35, -39, -56, -58, -68 y -73 y VPH-BR-43, -61, -62/81 y -72 
Los datos evidenciaron una elevada concordancia entre los resultados del ensayo E7-mPCR y PCR de L1 $(95,1 \%)$ con un valor de $\mathrm{K}=0,88$, demostrando una excelente concordancia diagnóstica. Además, se obtuvo un
$100 \%$ de reproducibilidad a partir de las 49 muestras que se procesaron por duplicado, encontrándose mayor número de infecciones por VPH -31, -33 y -52 en el 4,9\% con la detección de E7 (figura 2).

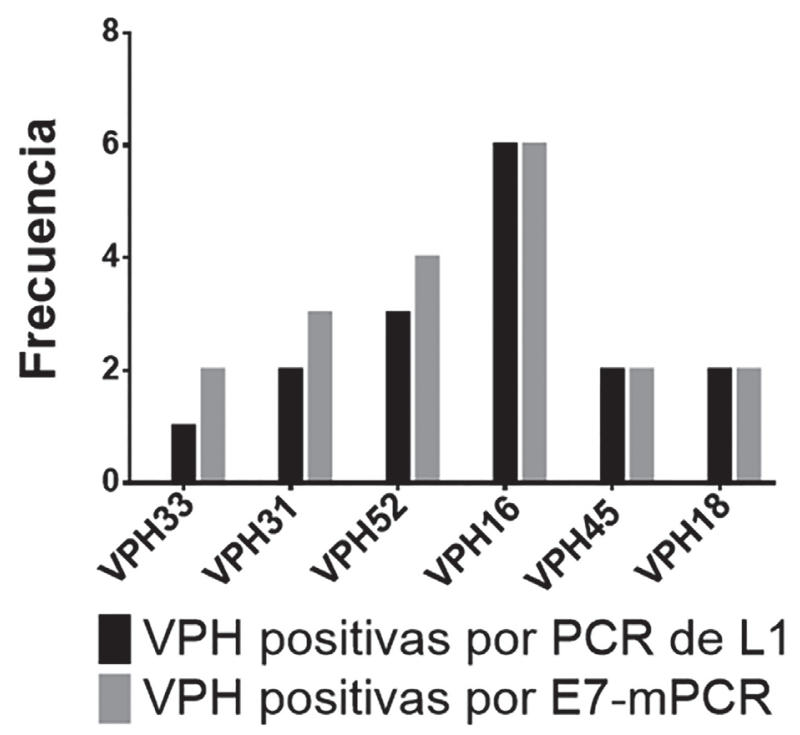

\begin{tabular}{cccc}
\hline Concordancia & $\begin{array}{c}\text { Concordancia } \\
\text { esperada }\end{array}$ & Kappa & $\begin{array}{c}\text { Error } \\
\text { estándar }\end{array}$ \\
\hline $95,08 \%$ & $58,96 \%$ & $\mathbf{0 , 8 8 0 2}$ & 0,1271 \\
\hline
\end{tabular}

Figura 2. Frecuencia de infección por seis genotipos de VPH-AR y concordancia entre los ensayos PCR de L1 y E7-mPCR

Fuente: elaboración propia.

\section{Discusión}

El número de muestras discordantes entre ambos métodos permitió detectar un $15,8 \%$ de falsos negativos por parte de la PCR de L1, lo cual coincide con lo expresado en la literatura. De acuerdo con los esquemas de manejo clínico actuales, a estas pacientes se les recomendó hacerse la citología cervical o una prueba de VPH en los siguientes 6 a 12 meses, con el fin de identificar la posible pre- sencia de infecciones persistentes por VPH-AR.

Dada la evidencia de resolución espontánea en el $90 \%$ de las infecciones por VPH (18), la detección inicial del virus no requiere automáticamente una evaluación colposcópica, ya que en las etapas iniciales la probabilidad de encontrar lesiones premalignas es baja, siendo suficiente una prueba de clasificación adicional (19). 
Probablemente, el porcentaje de falsos negativos se deba a la pérdida del gen L1 que ocurre durante el proceso de integración viral $(2,8)$. Durante este proceso, además ocurre la interrupción del ORF de los genes E1/E2, provocando un incremento en la expresión de E6 y E7, genes cuya presencia es esencial en el proceso de transformación maligna en el cuello uterino, ya que tienen la capacidad de modular el ciclo celular en las capas epiteliales superiores, así como estimular la proliferación celular en las capas basales y parabasales, razón por la cual la expresión descontrolada de estos oncogenes reguladores del ciclo celular conduce a lesiones premalignas y eventualmente progresan a cáncer en aquellas mujeres que no logran resolver la infección (12, 20-22).

En un estudio de lesiones cervicales de alto grado, se calculó la frecuencia de falsos negativos utilizando cebadores de la región L1 en comparación con el empleo de cebadores específicos para las regiones E6/E7. Los resultados mostraron que en las infecciones por VPH-16 el 0,3\% de las neoplasias intraepiteliales cervicales (NIC) grado 2 y el 3,94\% de NIC 3 fueron negativas por L1 y positivas por E6/E7 (23). Asimismo, se ha encontrado que particularmente el ensayo con L1 omite el 8,3\% de las infecciones por VPH-16 y el 27,9\% de infecciones por VPH-18 (24).

Otros estudios de comparación entre PCR con cebadores consenso de L1 (MY09/11) y PCR con cebadores de genotipo específico E6/E7 evidenciaron que el 10,9\% de las infecciones por VPH-AR no son detectadas por PCR de
L1, mientras que por PCR de E6/E7 sí es posible (7).

Claramente, la variabilidad en la sensibilidad de detección es una de las mayores desventajas de estos ensayos, principalmente como consecuencia de la pérdida de L1 durante la integración viral, aunque también debido a la degradación del ADN o a la falta de coincidencia en la alineación de los cebadores (24). La comparación de estos dos métodos podría proporcionar información acerca de la integración del VPH en el genoma de la célula hospedadora, lo cual es de gran importancia dado que se ha demostrado que la integración viral produce alteraciones en vías que pueden resultar en el crecimiento del tumor, como es el caso de la ruta mediada por proteínas Ras con potencial oncogénico, es decir, puede generar mutaciones conductoras en la carcinogénesis cervical y además promover la expresión de los oncogenes E6 y E7 (25-27).

Adicionalmente, se ha encontrado que en pacientes con NIC 1 existe una mayor expresión de la proteína L1 que en pacientes con NIC 2, NIC 3 o carcinoma in situ; esto sugiere que la expresión de L1 tiene una relación inversa con el grado de lesiones cervicales, es decir, la deficiencia de L1 se puede atribuir a la progresión de las lesiones. De esta manera, su ausencia sería un marcador para la predicción de CCU $(10,28)$. Por lo tanto, este ensayo tiene potencial aplicabilidad en la estratificación del riesgo, en la determinación de la persistencia de infección por VPH-AR $y$ en el control y seguimiento post-tratamiento (29). 
Por otro lado, el 95,5\% (42 de 44) de las muestras negativas para los seis genotipos de VPH-AR, pero positivas para otros VPH-AR o VPH-BR (incluyendo de genotipo indeterminado) por PCR de L1, fueron concordantemente negativas por E7-mPCR, esto llevaría a que esta prueba tenga una excelente especificidad para reconocer los genotipos de $\mathrm{VPH}$, la cual puede explicarse por el uso de oligonucleótidos específicos de genotipo en lugar de oligonucleótidos consenso, ya que la coamplificación de L1 de diferentes genotipos de VPH compite con la amplificación de los genotipos de VPH-AR. Si bien existe una limitación en la cantidad de genotipos de VPH detectados por E7-mPCR, los oligonucleótidos de genotipos específicos de VPH reducen la competencia para la amplificación del ADN de múltiples infecciones por VPH (30).

La limitación en la cantidad de genotipos estudiados podría superarse por medio de un sistema multiparamétrico, como el empleado en el estudio de detección y genotipificación del VPH por PCR Multiplex de L1 y tecnología Luminex en mujeres colombianas con citología anormal, donde la matriz de Luminex permitió la detección de 27 genotipos de VPH y además mostró una sensibilidad significativamente más alta en comparación con la hibridación reversa en fase sólida ( $R L B$, reverse line blotting) (31). Otra limitación tiene que ver con la falta de secuenciación de los productos de PCR para corroborar los resultados discordantes entre ambas pruebas. Se tendrá en cuenta este soporte de validación biológica y molecular para futuros estudios en la medida en que se estandaricen nuevas pruebas multiplex y se aumente la cobertura de los genotipos de VPHAR a analizar.

\section{Conclusiones}

A pesar de que la citología disminuye la incidencia de CCU (32), el alto porcentaje de falsos negativos refleja su baja sensibilidad y la necesidad de múltiples citologías para la detección temprana de lesiones precancerosas. Por esta razón, para avanzar en la tamización del CCU es necesaria una prueba lo suficientemente sensible, específica y con un alto valor predictivo negativo que detecte oportunamente el agente causal del CCU, que permita intervalos de detección más espaciados cuando los resultados son negativos y que disminuya los costos, que permita una mayor cobertura y tratamientos más oportunos. Las técnicas moleculares para la genotipificación de VPH ofrecen estas ventajas en comparación con la citología (33, 34 ), además de una mayor protección (de 60 a $70 \%$ ) contra el carcinoma invasivo de cuello uterino (35) y una alta sensibilidad en la detección de lesiones glandulares en mujeres VPH positivas con resultados normales en la citología $(36,37)$.

De las diferentes técnicas moleculares disponibles para la genotipificación del $\mathrm{VPH}$, la que se usa con mayor frecuencia es la PCR, principalmente empleando cebadores consenso $(38,39)$; sin embargo, se ha demostrado que los conjuntos de cebadores específicos son mejores para la genotipificación de VPH-AR (7, 40). Al considerar esto, el presente estudio desarrolló una MPCR con cebado- 
res específicos para el oncogén E7 de los seis genotipos VPH-AR más frecuentes, en la que los amplificados se diferenciaron en función de su tamaño en pares de bases, sin necesidad de procesamientos adicionales, se redujeron tiempos y costos en la identificación en comparación con otros métodos que requieren un procesamiento adicional, ya sea en digestión con enzimas de restricción (41), hibridación (42) o análisis de secuencia (43).

Adicionalmente, se pudo comprobar que un ensayo para la detección del gen L1 puede omitir infecciones que potencialmente evolucionen a fenotipos malignos, por esto las pruebas de detección y genotipificación de VPH que detectan preferentemente genes que se mantienen y contribuyen en la transformación maligna del epitelio infectado, como es el caso del oncogén E7, pueden ofrecer una mayor sensibilidad en la genotipificación de los VPH-AR.

Finalmente, este ensayo puede ser una herramienta diagnóstica más sensible, rápida y económica para detectar los seis genotipos de VPH-AR más fre- cuentes, cuyo siguiente nivel de aplicación es trasladarse a un sistema de alto desempeño multiparamétrico tipo Luminex ${ }^{\oplus}$, esta plataforma es más robusta y permite procesar gran cantidad de muestras y ampliar la cobertura de los genotipos de VPH-AR. Asimismo, se deben realizar estudios de validación de la técnica para que posteriormente se pueda utilizar para el diagnóstico temprano de CCU.

\section{Agradecimientos}

Este trabajo es financiado por Colciencias y la Universidad Industrial de Santander.

\section{Consideraciones éticas}

Investigación anidada al proyecto Colciencias 0012435 con aprobación del comité de ética del Instituto de Salud de Bucaramanga, ISABU.

\section{Conflicto de intereses}

Los autores no declaran conflicto de intereses. 


\section{Referencias bibliográficas}

1. Hausen H. Papillomavirus infections: a major cause of human cancers. Biochim Biophys Acta - Rev Cancer [Internet]. 1996 oct. 9 [citado 2019 abr. 3];1288(2):F55-78. Disponible en: https:// www.sciencedirect.com/science/article/ abs/pii/0304419X96000200?via\%3Dihub

2. Walboomers J, Jacobs M., Manos M, Bosch F, Kummer J, Shah K, et al. Human papillomavirus is a necessary cause of invasive cervical cancer worldwide. J Pathol [Internet]. 1999 sept. 1 [citado 2019 abr. 3];189(1):129. Disponible en: http://doi.wiley. com/10.1002/\%28SICI\%2910969896\%28199909\%29189\%3A1\%3C12\% 3A\%3AAID-PATH431\%3E3.0.CO\%3B2-F

3. Parkin DM, Bray F, Ferlay J, Pisani P. Estimating the world cancer burden: Globocan 2000. Int J Cancer [Internet]. 2001 oct. 15 [citado 2019 abr. 3];94(2):153-6. Doi:10.1002/ijc.1440

4. Instituto Nacional de Cancerología. Ministerio de la Protección Social [Internet]. 2007 [citado 2019 abr. 3]. Disponible en: https://www.minsalud. gov.co/sites/rid/Lists/BibliotecaDigital/ RIDE/IA/INCA/Guia-tamizacion-cuello-uterino.pdf

5. Cuzick J, Clavel C, Petry K-U, Meijer CJ, Hoyer H, Ratnam S, et al. Overview of the European and North American studies on HPV testing in primary cervical cancer screening. Int J Cancer [Internet]. 2006 sept. 1 [citado 2018 sept. 1];119(5):1095101. Disponible en: http://www.ncbi.nlm. nih.gov/pubmed/16586444

6. Sarian LO, Derchain SF, Naud $P$, Roteli C, Longatto A, Tatti S, et al. Evaluation of visual inspection with acetic acid (VIA), Lugol's iodine (VILI), cervical cytology and HPV testing as cervical screening tools in Latin America. J Med Screen [Internet]. 2005 sept. 23 [citado 2019 abr. 3];12(3):142-9. Disponible en: http://www.ncbi.nlm.nih.gov/ pubmed/16156945
7. Depuydt C, Boulet G, Horvath C, Benoy I, Vereecken A, Bogers J. Comparison of MY09/11 consensus PCR and type-specific PCRs in the detection of oncogenic HPV types. J Cell Mol Med [Internet]. 2007 jul. 1 [citado 2018 sept. 1];11(4):881-91. doi: 10.1111/j.1582-4934.2007.00073.x

8. Gheit T, Landi S, Gemignani F, Snijders PJ, Vaccarella S, Franceschi S, et al. Development of a sensitive and specific assay combining multiplex PCR and DNA microarray primer extension to detect high-risk mucosal human papillomavirus types. J Clin Microbiol [Internet]. 2006 jun. 1 [citado 2018 sept. 1];44(6):2025-31. Disponible en: http://www.ncbi.nlm.nih.gov/ pubmed/16757593

9. Hernández D. Diseño y estandarización de un sistema PCR-SSCP del gen E6 para detección y tipificación del virus del papiIoma humano (VPH). [citado 2018 my. 26]; Disponible en: http://www.saber.ula.ve/ bitstream/handle/123456789/38763/Hernandez2010.pdf; jsessionid=63A66FEDBE87D5F7A180E00400588350?sequence $=1$

10. Bin H, Ruifang W, Ruizhen L, Yiheng $L$, Zhihong L, Juan L, et al. Detention of HPV L1 Capsid Protein and hTERC Gene in Screening of Cervical Cancer. Iran J Basic Med Sci [Internet]. 2013 jun. [citado 2018 my. 26];16(6):797-802. Disponible en: http://www.ncbi.nlm.nih.gov/ pubmed/23997907

11. Paes EF, de Assis AM, Teixeira CSC, Aoki FH, Teixeira JC. Development of a multiplex PCR test with automated genotyping targeting E7 for detection of six high-risk human papillomaviruses. PLoS One [Internet]. 2015 jun. 18 [citado 2018 my. 26];10(6):e0130226. Disponible en: http://dx.plos.org/10.1371/journal. pone.0130226

12. Doorbar J, Egawa N, Griffin H, Kranjec C, Murakami I. Human papillomavirus molecular biology and disease association. Rev Med Virol [Internet]. 2015 mzo. [ci- 
tado 2018 my. 26];25:2-23. Doi: 10.1002/ rmv.1822

13. Hesselink AT, Berkhof J, van der Salm $\mathrm{ML}$, van Splunter AP, Geelen TH, van Kemenade FJ, et al. Clinical validation of the HPV-risk assay, a novel real-time PCR assay for detection of high-risk human papillomavirus DNA by targeting the E7 region. J Clin Microbiol [Internet]. 2014 mzo. 1 [citado 2018 my. 26];52(3):890-6. Disponible en: http://www.ncbi.nlm.nih. gov/pubmed/24391196

14. Torrado G, Rincón B, Martínez RA. Genotipificación del virus de papiloma humano en mujeres de la comuna norte de Bucaramanga. Salud UIS [Internet]. 2018 [citado 2019 abr. 8];50(3). Disponible en: https://revistas.uis.edu.co/index.php/ revistasaluduis/article/view/8526/8639

15. Bouvard V, Baan R, Straif K, Grosse $Y$, Secretan B, El Ghissassi F, et al. A review of human carcinogens--Part B: biological agents. Lancet Oncol [Internet]. 2009 abr. 1 [citado 2019 mzo. 11];10(4):321-2. Disponible en: http://www.ncbi.nlm.nih.gov/ pubmed/19350698

16. Herraez E, Álvarez M, Navarro G, Esquivias J, Alonso S, Aneiros J, et al. HPV Direct Flow CHIP: A new human papillomavirus genotyping method based on direct PCR from crude-cell extracts. J Virol Methods [Internet]. 2013 oct. [citado 2019 abr. 3];193(1):9-17. Disponible en: http:// www.ncbi.nlm.nih.gov/pubmed/23680093

17. Miller SA, Dykes DD, Polesky HF. A simple salting out procedure for extracting DNA from human nucleated cells. Nucleic Acids Res [Internet]. 1988 febr. 11 [citado 2018 sept. 17];16(3):1215. Disponible en: http://www.ncbi.nlm.nih.gov/ pubmed/3344216

18. Sherman ME, Lorincz AT, Scott DR, Wacholder S, Castle PE, Glass AG, et al. Baseline cytology, human papillomavirus testing, and risk for cervical neoplasia: a 10-year cohort analysis. J Natl Cancer Inst [Internet]. 2003 en. 1 [citado 2019 abr.
19. Naucler P, Ryd W, Tornberg S, Strand A, Wadell G, Elfgren K, et al. Efficacy of HPV DNA testing with cytology triage and/ or repeat HPV DNA testing in primary cervical cancer screening. JNCI J Natl Cancer Inst [Internet]. 2009 en. 21 [citado 2019 abr. 3];101(2):88-99. Disponible en: http:// www.ncbi.nlm.nih.gov/pubmed/19141778

20. Bernard BA, Bailly C, Lenoir MC, Darmon $M$, Thierry $F$, Yaniv $M$. The human papillomavirus type 18 (HPV18) E2 gene product is a repressor of the HPV18 regulatory region in human keratinocytes. $J$ Virol [Internet]. 1989 oct. [citado 2019 abr. 3];63(10):4317-24. Disponible en: http:// www.ncbi.nlm.nih.gov/pubmed/2476572

21.Thierry F, Yaniv M. The BPV1-E2 trans-acting protein can be either an activator or a repressor of the HPV18 regulatory region. EMBO J [Internet]. 1987 [citado 2019 abr. 3];6(11):3391. Disponible en: https://www.ncbi.nlm.nih.gov/pmc/ articles/PMC553796/

22. Pett $\mathrm{M}$, Coleman N. Integration of high-risk human papillomavirus: a key event in cervical carcinogenesis? J Pathol [Internet]. 2007 ag. 1 [citado 2018 sept. 1];212(4):356-67. Doi: 10.1002/path.2192.

23. Roberts CC, Tadesse AS, Sands J, Halvorsen T, Schofield TL, Dalen A, et al. Detection of HPV in Norwegian cervical biopsy specimens with type-specific PCR and reverse line blot assays. J Clin Virol [Internet]. 2006 ag. 1 [citado 2018 sept. 1];36(4):277-82. Disponible en: https:// www.sciencedirect.com/science/article/ pii/S1386653206001296

24. Tjalma WA, Depuydt CE. Cervical cancer screening: which HPV test should be used-L1 or E6/E7? Eur J Obstet Gynecol Reprod Biol [Internet]. 2013 sept. 1 [citado 2018 sept. 1];170(1):45-6. Disponible en: https:// www.sciencedirect.com/science/article/ pii/S030121151300287X?via\%3Dihub

25. Melsheimer $P$, Vinokurova $S$, Wentzensen N, Bastert G, von Knebel Doeberitz M. DNA aneuploidy and integration of human papillomavirus type 16 e6/e7 oncogenes ncbi.nlm.nih.gov/pubmed/12509400 
in intraepithelial neoplasia and invasive squamous cell carcinoma of the cervix uteri. Clin Cancer Res [Internet]. 2004 my. 1 [citado 2019 abr. 3];10(9):3059-63. Disponible en: http://www.ncbi.nlm.nih.gov/ pubmed/15131043

26. Liu Y, Lu Z, Xu R, Ke Y. Comprehensive mapping of the human papillomavirus (HPV) DNA integration sites in cervical carcinomas by HPV capture technology. Oncotarget [Internet]. 2016 febr. 2 [citado 2019 abr. 3];7(5):5852-4. Disponible en: http://www.ncbi.nlm.nih.gov/ pubmed/26735580

27. Bodelon C, Vinokurova S, Sampson JN, den Boon JA, Walker JL, Horswill MA, et al. Chromosomal copy number alterations and HPV integration in cervical precancer and invasive cancer. Carcinogenesis [Internet]. 2016 febr. [citado 2019 abr. 3];37(2):188-96. Disponible en: http:// www.ncbi.nlm.nih.gov/pubmed/26660085

28. Arafa M, Boniver J, Delvenne P. Detection of Hpv-induced Cervical (pre) Neoplastic Lesions: A Tissue Microarray (tma) Study. Appl Immunohistochem \&amp [Internet]. 2008 oct. 1 [citado 2018 my. 27];16(5):422-32. Disponible en: https://insights. ovid. com/pubmed?pmid $=18542030$

29. Abreu AL, Souza RP, Gimenes F, Consolaro ME. A review of methods for detect human Papillomavirus infection. Virol J [Internet]. 2012 nov. 6 [citado 2019 abr. 3];9(1):262. Disponible en: http://virologyj.biomedcentral.com/ articles/10.1186/1743-422X-9-262

30. Schmitt M, Dondog B, Waterboer T, Pawlita M, Tommasino M, Gheit T. Abundance of multiple high-risk human papillomavirus (HPV) infections found in cervical cells analyzed by use of an ultrasensitive HPV genotyping assay. J Clin Microbiol [Internet]. 2010 en. 1 [citado 2018 sept. 1];48(1):143-9. Disponible en: http://www. ncbi.nlm.nih.gov/pubmed/19864475

31. García DA, Cid-Arregui A, Schmitt M, Castillo M, Briceño I, Aristizábal FA. Highly sensitive detection and genotyping of hpv by pcr multiplex and luminex tech- nology in a cohort of Colombian women with abnormal cytology. Open Virol J [Internet]. 2011 [citado 2019 abr. 3];5:70-9. Disponible en: http://www.ncbi.nlm.nih. gov/pubmed/21769306

32. Anttila A, Nieminen P. Cervical cancer screening programme in Finland. Eur J Cancer [Internet]. 2000 nov. [citado 2019 abr. 3];36(17):2209-14. Disponible en: http://linkinghub.elsevier.com/retrieve/pii/ S0959804900003117

33. Dillner J, Rebolj M, Birembaut P, Petry K-U, Szarewski A, Munk C, et al. Long term predictive values of cytology and human papillomavirus testing in cervical cancer screening: joint European cohort study. BMJ [Internet]. 2008 oct. 13 [citado 2019 abr. 3];337:a1754. Disponible en: http:// www.ncbi.nlm.nih.gov/pubmed/18852164

34. Ogilvie GS, Krajden M, van Niekerk $D$, Smith LW, Cook D, Ceballos $K$, et al. HPV for cervical cancer screening (HPV FOCAL): Complete Round 1 results of a randomized trial comparing HPV-based primary screening to liquid-based cytology for cervical cancer. Int J Cancer [Internet]. 2017 en. 15 [citado 2019 abr. 3];140(2):440-8. Doi: 10.1002/ijc.30454

35. Ronco G, Dillner J, Elfström KM, Tunesi S, Snijders PJF, Arbyn M, et al. Efficacy of HPV-based screening for prevention of invasive cervical cancer: follow-up of four European randomised controlled trials. Lancet [Internet]. 2014 febr. 8 [citado 2019 abr. 3];383(9916):524-32. Disponible en: http://www.ncbi.nlm.nih.gov/ pubmed/24192252

36. Huh WK, Ault KA, Chelmow D, Davey DD, Goulart RA, Garcia FAR, et al. Use of primary high-risk human papillomavirus testing for cervical cancer screening. Obstet Gynecol [Internet]. 2015 febr. [citado 2019 abr. 3];125(2):330-7. Disponible en: http://insights.ovid.com/ crossref?an $=00006250-201502000-00008$

37. Harari A, Chen Z, Burk RD. Human papillomavirus genomics: past, present and future. In: Current problems in dermatology [Internet]. 2014 [citado 2019 abr. 3]. 
p. 1-18. Disponible en: http://www.ncbi. nlm.nih.gov/pubmed/24643174

38. Fuessel AL, He Q, Rady PL, Zhang L, Grady J, Hughes TK, et al. Nested PCR with the PGMY09/11 and GP5+/6+ primer sets improves detection of HPV DNA in cervical samples. J Virol Methods [Internet]. 2004 dic. 1 [citado 2019 abr. 3];122(1):87-93. Disponible en: http:// www.ncbi.nlm.nih.gov/pubmed/15488625

39. Castle PE, de Sanjosé S, Qiao Y, Belinson JL, Lazcano-Ponce E, Kinney W. Introduction of human papillomavirus DNA screening in the world: 15 years of experience. Vaccine [Internet]. 2012 nov. 20 [citado 2019 abr. 3];30:F117-22. Disponible en: http://www.ncbi.nlm.nih.gov/ pubmed/23199954

40. Sotlar K, Diemer D, Dethleffs A, Hack Y, Stubner A, Vollmer N, et al. Detection and typing of human papillomavirus by e6 nested multiplex PCR. J Clin Microbiol [Internet]. 2004 jul. [citado 2019 abr. 3];42(7):3176-84. Disponible en: http:// www.ncbi.nlm.nih.gov/pubmed/15243079
41. Maver PJ, Poljak M, Seme K, Kocjan BJ. Detection and typing of low-risk human papillomavirus genotypes HPV 6 , HPV 11, HPV 42, HPV 43 and HPV 44 by polymerase chain reaction and restriction fragment length polymorphism. J Virol Methods [Internet]. 2010 oct. [citado 2019 abr. 3];169(1):215-8. Disponible en: http://www.ncbi.nlm.nih.gov/ pubmed/20637805

42. Shen-Gunther J, Rebeles J. Genotyping human papillomaviruses: Development and evaluation of a comprehensive DNA microarray. Gynecol Oncol [Internet]. 2013 mzo. [citado 2019 abr. 3];128(3):433-41. Disponible en: http://www.ncbi.nlm.nih.gov/ pubmed/23200917

43. Militello V, Lavezzo E, Costanzi G, Franchin E, Di Camillo B, Toppo S, et al. Accurate human papillomavirus genotyping by 454 pyrosequencing. Clin Microbiol Infect [Internet]. 2013 oct. [citado 2019 abr. 3];19(10):E428-34. Disponible en: http://www.ncbi.nlm.nih.gov/ pubmed/23573945 